\title{
Experimental Study for Evacuated Tube Solar Collector with/without a Compound Parabolic Concentrator
}

\author{
Xu Jia ${ }^{1,}$, Guoxin $\mathrm{Wu}^{1}$, Tzer-Ming Jeng ${ }^{2}$, Sheng-Chung Tzeng ${ }^{2}$ and Weikai Huang ${ }^{2}$ \\ ${ }^{1}$ Key Laboratory of Modern Measurement \& Control Technology, Ministry of Education, Beijing Information Science \& \\ Technology University, China \\ ${ }^{2}$ Department of Mechanical Engineering, Chienkuo Technology University, Taiwan \\ ${ }^{*}$ Corresponding author
}

\begin{abstract}
This paper explored the thermal performance of evacuated tube solar collector with/without a semicircular compound parabolic concentrator (CPC). The configurations of tested systems were: (1) the system without CPC, (2) the system with Model A CPC (3) the system with Model B CPC. This work investigated and compared the thermal efficiency of the evacuated tube solar collector with the CPC by the surface temperature measurements of the evacuated tube solar collector and temperature difference comparison in water tank. Under the following experimental conditions, experimental data indicated that thermal performance of back surface for evacuated tube solar collector can be improved by CPC assuredly. Furthermore, we discovered that two systems with Model A CPC and Model B CPC can improve the efficiency of water temperature in water tank than the system without CPC. The test results showed that CPC can improve thermal efficiency of evacuated tube solar collector effectively while thermal performance was effected by radial size of CPC. To some extent, the bigger the radial size of the CPC, the higher the thermal efficiency. These experimental results provided basis and reference for practical application of Solar Water Heater (SWH).
\end{abstract}

Keywords-evacuated tube solar collector; compound parabolic concentrator; thermal performance; solar water heater (SWH)

\section{INTRODUCTION}

Recently, solar energy has become more and more popular among variety of energy, which is an important component of the human using energy and develops continuously. It has many advantages, such as: can be directly exploited and utilized, protect the environment, can be reproduced and etc. The use of solar energy have solar-thermal conversion and photoelectric conversion in two ways. While, the photoelectric conversion is generally applied to ordinary family, for instance: Solar Water Heater, solar drier, an air conditioning system using solar energy, solar cooker and etc. At present, the most used solar collectors basically includes four species: flat plate solar collector, evacuated tube solar collector, ceramic solar collectors and compound parabolic concentrator. This paper mainly focuses on the research of evacuated tube solar collector and the related investigation in domestic and abroad are described as follows:

Tao Tao et al.[1]propose a novel design method and operation principle about a new trough solar concentrator. In their experiment, some crucial design parameters are given and optimized. Compared with the traditional parabolic trough solar concentrator, they point out that this trough solar concentrator with an excellent design method can improve the overall thermal performance. Especially increase the configuration intensity of the reflection surface. Furthermore, the working performance and environment of high-temperature solar receiver are improved. Harjit Singh and Eames[2] point out that heat transfer mechanism is extremely complex in cavities of compound parabolic concentrator. They research the natural convective heat transfer characteristics in compound parabolic concentrator cavities with different shapes. In order to prevent heat from dissipating caused by convection effect, baffle is brought within the cavity. Under these circumstance, more radiant heat can be absorbed and accumulated even the thermal performance. Yuehong Su et al.[3] explore the comparison on the thermal performance of solar collector from the following compound parabolic concentrator(CPC). They are lens-walled CPC, mirror CPC and dielectric solid CPC respectively. The back of the lens-walled CPC is covered specular coating. With optical analysis software simulation, the result indicate that the lens-walled CPC can achieve about $80 \%$ of the solid CPC's performance and 20-30\% larger than the mirror CPC. Kessentini and Bouden[4]exploit a numerical calculation method(numerical code) to predict the thermal behavior of a double tank integrated collector within compound parabolic concentrator(CPC). Meanwhile, they set up the experimental device outside to measure and verify the accuracy of numerical calculation. $\mathrm{Li}$ et al.[5]build a performance testing combining compound parabolic concentrator(CPC) with the U-shape evacuated tubes under $80-250^{\circ} \mathrm{C}$. By calculating and analyzing experimental results, they point out that deep compound parabolic concentrator need to adjust the angle repeatedly in one day so that more sun light can be received. While, the shallow one need to adjust the angle in one year as well to get the best thermal efficiency. Under the best angle, the deep one can approach $46 \%$ thermal efficiency, $40 \%$ higher than the shallow one. Miriam Sánchez et al.[6]design an ultrahigh solar concentrator and carry out optical analysis to it. Meanwhile, technical feasibility of using solar energy is validated, especially high temperatures with relatively simple devices. The main application of the newly designed device is focused on the degradation of plastic materials used in everyday products. They discover that the thermal efficiency of ultrahigh 
solar radiation devices will be improved by using those materials with optical, thermal and mechanical properties. PinYang Wang et al.[7]do the experiment on a new-type all-glass evacuated tubular solar air heater with simplified compound parabolic concentrator (CPC).They attempt to simulate and analyze the performance of this device which include evacuated tube solar collector and high-temperature air heaters with simplified CPC and U-shaped tube heat exchanger. Providing air with moderate temperature of $150-200{ }^{\circ} \mathrm{C}$ for industrial production is the main application for the set of equipment. The experimental results show that the present heater system has excellent performance of solar collecting. Especially in winter, under this circumstance that is relatively large air flow rate, outlet air temperature of this system can reach even surpass $200^{\circ} \mathrm{C}$. The simulation results of the experiment can be applied to engineering. C.Chang et al.[8]research the turbulent heat transfer in solar thermal absorber tubes by experimental testing and numerical analysis. They find that the absorber tube is different from other tubes because of its heat transfer performance. To their surprise, half of the circumference surface of the absorber tube is heated with the non-uniform heat flux while the other half is insulated. The experiment reveal the turbulent convective heat transfer performance in the solar absorber tube by relative methods, such as computational fluid dynamics and etc. The results show that the temperature distribution of fluid and tube wall is nonuniform, no matter in axial or other directions. Dittus-Boelter correlation is still available to calculate the heat transfer in an absorber tube with non-uniform heat flux. Sukruedee Sukchai et al.[9]design and fabricate a system which can test thermal efficiency of the heat pipe evacuated tube with compound parabolic concentrator. Not adjusting the direction of the CPC to track the sun, the system can produce hot water over a period of time. That's the advantage of it. What's more, they must check the thermal performance of solar collector so as to make sure the efficiency of the system. It is crucial to the end users. By testing and formulating a mathematical model, they find that the thermal efficiency produced by the system is equal to $78 \%$ and the monthly average energy of the CPC produced throughout the year is equal to $286.16 \mathrm{kWh}$ or equal to $3,433.87 \mathrm{kWh} /$ year. Jian Wang et al.[10]research mesotherm solar collector with all-glass evacuated tubes and discover that they can obtain concentrate solar radiation by smooth aluminum compound parabolic concentrator. Meanwhile, the solar reflectance approaches 0.91 and the thermal efficiency ascends from $25{ }^{\circ} \mathrm{C}$ to $150{ }^{\circ} \mathrm{C}$. Yuechao Deng et al.[11]propose an innovation in order to overcome the shortcomings of the existing solar collectors. An unfamiliar flat plate solar water heater (SWH) using micro heat pipe array (MHPA) with sprayed solar selective coating on it is applied. The MHPA are packed together as the absorber of collector which has many advantages, such as resistance to freezing, prevention of leakage, elimination of welding and etc. The experiment on testing thermal performance of SWH is carried out under different weather conditions in Beijing. The test results show that the daily effective heat gains on the three typical days in different seasons are different respectively. The data of measurement reveal that the novel SWH has excellent thermal performance.
In order to overcome the shortcomings of the existing evacuated tube solar collector, a novel solution is proposed. With the compound parabolic concentrator surrounding the evacuated tube solar collector, it can fully absorb the solar energy reflecting back. Under these conditions, the back surface of the evacuated tube solar collector can be used for collecting more heat. Furthermore, the thermal performance of evacuated tube solar collector can be improved.

\section{DESCRIPTION OF THE EXPERIMENTS}

The device of this experiment is shown in Figure I which consists of six parts: (1)halogen lamps, (2)evacuated tube solar collector, (3)semicircular compound parabolic concentrator, (4)water tank, (5)data recorder and (6)computer. Four parts of experimental device are described specifically as follows:

(1) halogen lamps: $3 \times 3$ array of halogen lamps,the power consumption of each lamp is $500 \mathrm{~W} /$ side length $11.8 \mathrm{~cm} \times 11.8 \mathrm{~cm}$.

(2) evacuated tube solar collector: the dimensions of $172 \mathrm{~cm}$ length/diameter $7 \mathrm{~cm}$.

(3) semicircular compound parabolic concentrator

- the system with Model A compound parabolic concentrator which is a metal semicircular tube with the dimensions of $145 \mathrm{~cm}$ length, $15 \mathrm{~cm}$ inner diameter and $16 \mathrm{~cm}$ outer diameter.

- the system with Model B compound parabolic concentrator which is a metal semicircular tube with the dimensions of $145 \mathrm{~cm}$ length, $47.7 \mathrm{~cm}$ inner diameter and $48.5 \mathrm{~cm}$ outer diameter.

(4) water tank: length $44 \mathrm{~cm}$, width $34 \mathrm{~cm}$ and height $50 \mathrm{~cm}$.

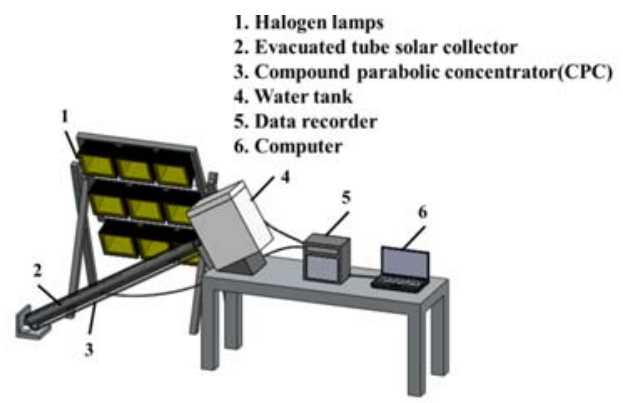

FIGURE I. DEVICE OF THE EXPERIMENT FOR EVACUATED TUBE SOLAR COLLECTOR

Figure II presents the relative dimension position between the test section and the light source (halogen lamps).

Figure III presents the dimension position of thermocouple distribution.

Figure IV presents the dimension between test section of evacuated tube solar collector and semicircular compound parabolic concentrator.

Figure $\mathrm{V}$ indicates the thermocouple distribution of evacuated tube solar collector.

Figure VI indicates the thermocouple distribution in water tank. 


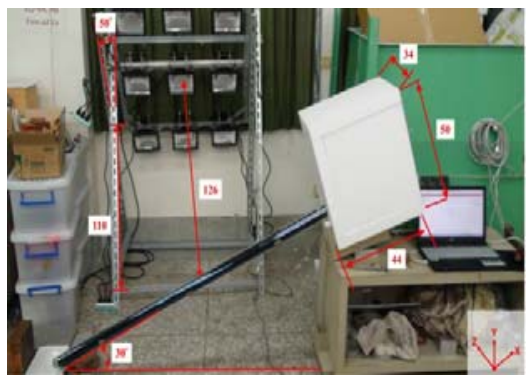

FIGURE II. RELATIVE DIMENSION POSITION BETWEEN THE TEST SECTION AND THE LIGHT SOURCE

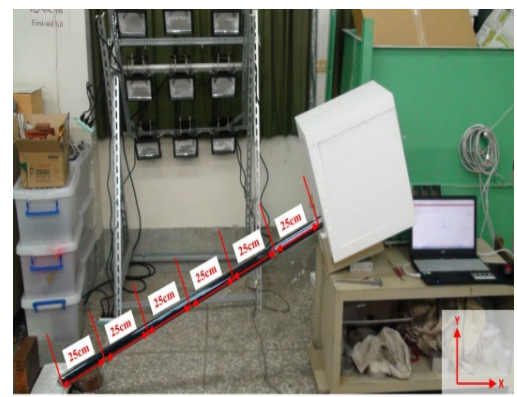

FIGURE III. DIMENSION POSITION OF THERMOCOUPLE DISTRIBUTION

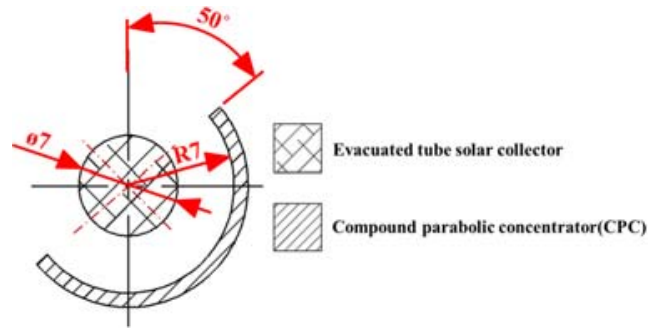

FIGURE IV. DIMENSION BETWEEN TEST SECTION OF EVACUATED TUBE SOLAR COLLECTOR AND SEMICIRCULAR COMPOUND PARABOLIC CONCENTRATOR

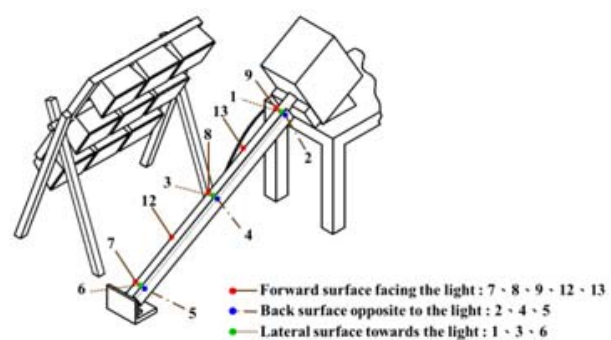

FIGURE V. THERMOCOUPLE DISTRIBUTION OF EVACUATED TUBE SOLAR COLLECTOR

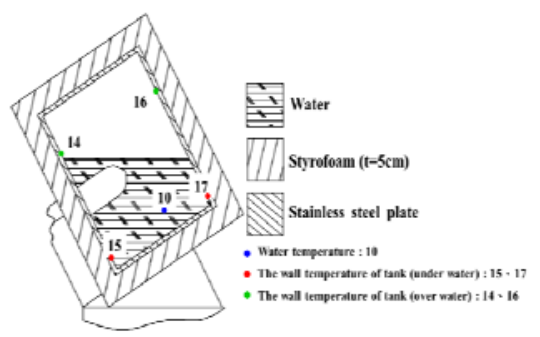

FIGURE VI. THERMOCOUPLE DISTRIBUTION IN WATER TANK
This experiment is based on 9 halogen lamps with $500 \mathrm{w}$ power consumption irradiating evacuated tube solar collector permanently for 90 minutes. The amount of water in the tested water tank is $5000 \mathrm{cc}$. The configurations of tested systems are there models, they are the system without the compound parabolic concentrator, the system with Model A compound parabolic concentrator and the system with Model B compound parabolic concentrator respectively. Figure VII shows the Model A compound parabolic concentrator, while Figure VIII shows the Model B compound parabolic concentrator. Testing the temperature of each point on thermocouple at fixed angle and water temperature in water tank, we can compare which model has the better thermal efficiency.

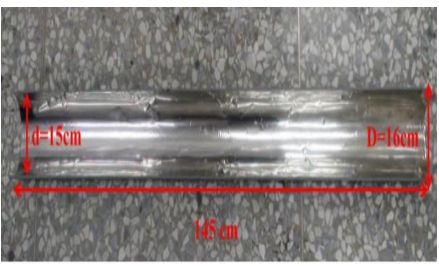

FIGURE VII. MODEL A COMPOUND PARABOLIC CONCENTRATOR

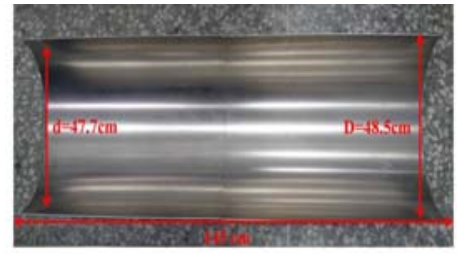

FIGURE VIII. MODEL B COMPOUND PARABOLIC CONCENTRATOR

\section{RESULTS AND DISCUSSION}

This work conduct three tests on the system without the compound parabolic concentrator, the system with Model A compound parabolic concentrator and the system with Model B compound parabolic concentrator respectively by using halogen lamps instead of sunlight and 90 minutes of continuous irradiation. Though analyzing the surface temperature of evacuated tube solar collector and water temperature in water tank, we can get $\triangle T . \triangle T$ is defined as the temperature difference between initial temperature and final temperature.

As we can see in Figure IX, the time variation for temperature of surface facing the light source, it indicates that the surface temperature has increased slightly for the system with compound parabolic concentrator(both Model A and Model B).

Figure $\mathrm{X}$ is the time variation for temperature of lateral surface towards the light source. Temperature variation is not wide with/without compound parabolic concentrator because the temperature of lateral surface is not influenced by halogen lamps at all.

Figure XI is the time variation for temperature of surface opposite to the light source. There are some significant differences which can be found. Compared with two systems which contain Model A compound parabolic concentrator and the other contain Model B compound parabolic concentrator, the temperature of back surface for the system without the compound parabolic concentrator is lower. While, difference 
between the system with Model A compound parabolic concentrator and the system with Model B compound parabolic concentrator is small. But, it can be discovered all the same. As is shown from these temperature curves, the temperature difference of Model A compound parabolic concentrator is higher than the Model B compound parabolic concentrator. It's worth reflecting that the temperature distribution point of surface opposite to the light source is three purely. Therefore, slight error appearing is a normal phenomenon. For the next phase of the experiment, optimal distribution of thermocouple deserve in-depth study to eliminate errors as much as possible.

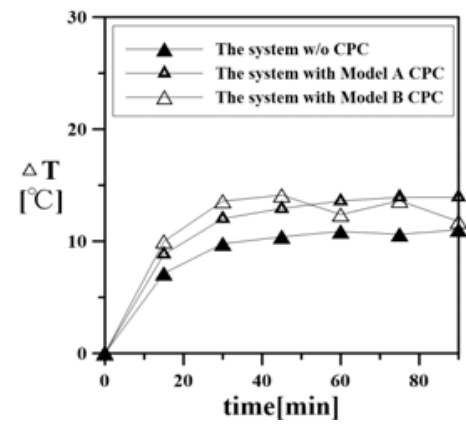

FIGURE IX. TIME VARIATION FOR TEMPERATURE OF SURFACE FACING THE LIGHT SOURCE

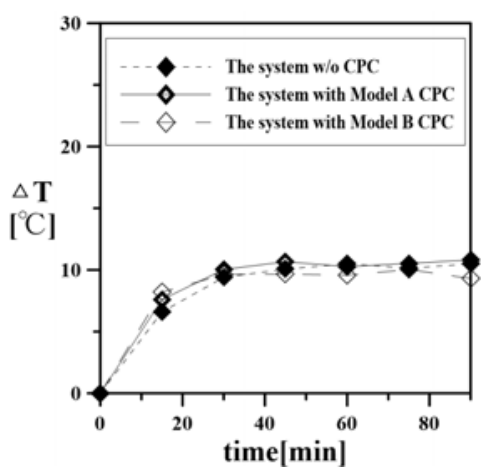

FIGURE X. TIME VARIATION FOR TEMPERATURE OF LATERAL SURFACE TOWARDS THE LIGHT SOURCE

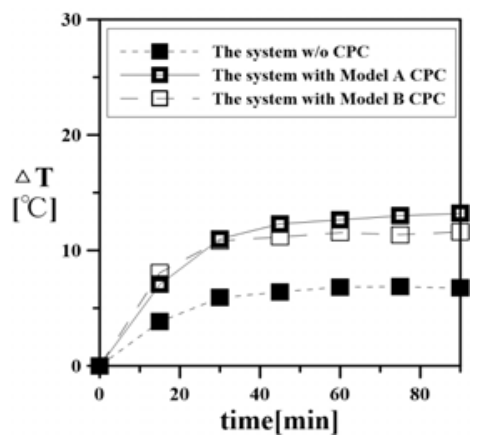

FIGURE XI. TIME VARIATION FOR TEMPERATURE OF SURFACE OPPOSITE TO THE LIGHT SOURCE

Figure XII shows the surface temperature distribution of evacuated tube solar collector with/without a compound parabolic concentrator (CPC). Experimental conditions are arranged as follows: $5000 \mathrm{cc}$ water in the tested water tank, ambient temperature $30.5^{\circ} \mathrm{C}$, with the halogen lamps instead of sunlight irradiating evacuated tube solar collector permanently for 90 minutes. Under these circumstance, we can get the detailed data of surface temperature for evacuated tube solar collector. As we can see from these temperature curves in Figure XII A) to Figure XII C), the surface temperature difference between the temperature distribution of forward surface in Figure XII A) and lateral surface in Figure XII B) is not large. While, temperature difference of back surface in Figure XII C) is obvious extremely.

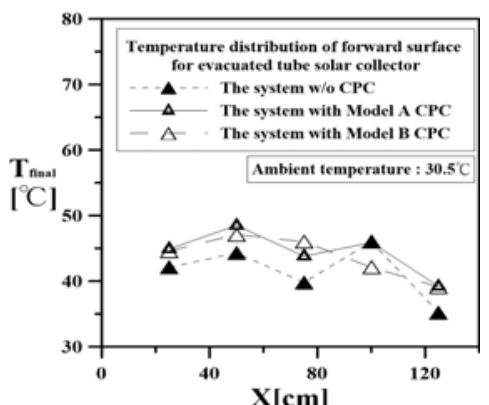

(A)

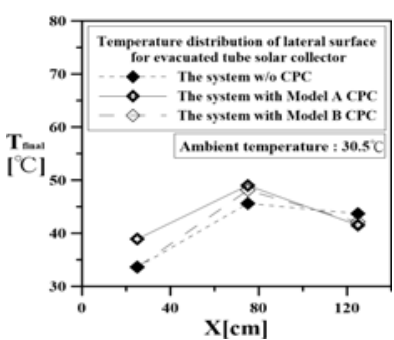

(B)

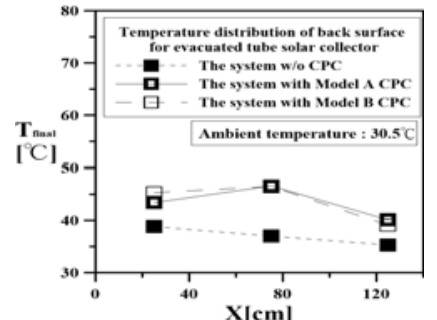

(C)
FIGURE XII. A) TO TEMPERATURE DISTRIBUTION OF FORWARD SURFACE/ B) LATERAL SURFACE/ C) BACK SURFACE

Figure XIII indicates the comparison of water temperature difference in water tank. We can get three sets of data about it. Based on the water temperature difference of the the system without compound parabolic concentrator and contrast with other two systems which contain Model A compound parabolic concentrator and the other contain Model B compound parabolic concentrator, we can compare the enhancement efficiency of water temperature in water tank from the three configurations of tested systems above. Though data analysis, we can discover that compared with configuration without compound parabolic concentrator, both the system with Model A compound parabolic concentrator and the system with Model B compound parabolic concentrator can improve water temperature efficiency about $20 \%$ and $110 \%$ respectively. Experimental data demonstrate that the system with compound parabolic concentrator can increase water temperature significantly. What's more, water temperature difference of the system with Model B is higher than the system with Model A. In the other words, Model B compound parabolic concentrator is superior to Model A compound parabolic concentrator on enhancement efficiency of water temperature. It is proved that thermal efficiency of evacuated tube solar collector with the semicircular compound parabolic concentrator can approach $200 \%$ efficiency. 


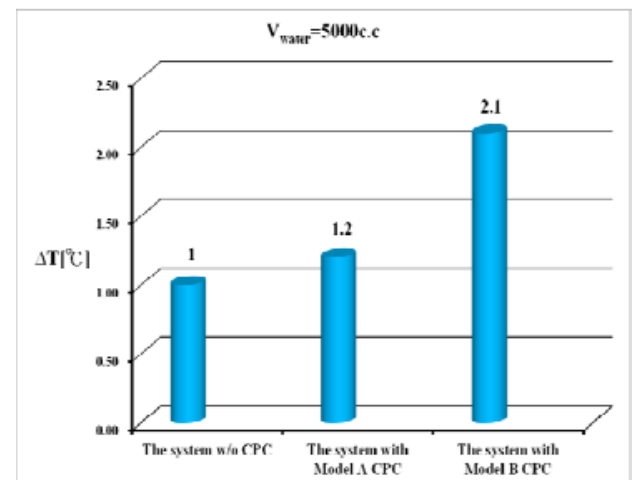

FIGURE XIII. COMPARISON OF WATER TEMPERATURE DIFFERENCE IN WATER TANK

\section{CONCLUSIONS}

This paper mainly describe thermal efficiency of evacuated tube solar collector influenced by the radial size of compound parabolic concentrator. Through experimental method, we can get relative data about surface temperature of the evacuated tube solar collector and water temperature difference in water tank. The configurations of tested systems were: (1) the system without the compound parabolic concentrator, (2) the system with Model A compound parabolic concentrator which was a metal semicircular tube with the dimensions of $145 \mathrm{~cm}$ length, $15 \mathrm{~cm}$ inner diameter and $16 \mathrm{~cm}$ outer diameter, (3) the system with Model B compound parabolic concentrator which was a metal semicircular tube with the dimensions of $145 \mathrm{~cm}$ length, $47.7 \mathrm{~cm}$ inner diameter and $48.5 \mathrm{~cm}$ outer diameter. In order to improve thermal efficiency of back surface for evacuated tube solar collector, we build the system with compound parabolic concentrator. Under these conditions, including using halogen lamps instead of sunlight, 90 minutes of continuous irradiation, testing indoor, the experimental data indicate that average temperature of surface opposite to the light source for evacuated tube solar collector with Model A compound parabolic concentrator and Model B compound parabolic concentrator were raised $17.3 \%$ and $18 \%$ respectively.

Furthermore, compared with three different configurations mentioned above for improving the efficiency of water temperature in water tank, we discovered that the system with Model A compound parabolic concentrator and Model B compound parabolic concentrator can improve water temperature efficiency about $20 \%$ and $110 \%$ respectively than the system without compound parabolic concentrator. It is proved that the compound parabolic concentrator indeed can effectively achieve the purpose of improving the thermal efficiency of evacuated tube solar collector. This study attempt to find a suitable configuration (the better compound parabolic concentrator) for the system to the deeper research in the future.

\section{REFERENCES}

[1] Tao T, Zheng H F, He K Y, Abdulkarim Mayere. A new trough solar concentrator and its performance analysis. Solar Energy, 2011(85): 198207.

[2] Harjit Singh, Philip C. Eames. A review of natural convective heat transfer correlations in rectangular cross-section cavities and their potential applications to compound parabolic concentrating (CPC) solar collector cavities. Applied Thermal Engineering, 2011(31): 2186-2196.
[3] Su Y H, Saffa B. Riffat, Pei G. Comparative study on annual solar energy collection of a novel lens-walled compound parabolic concentrator (lens-walled CPC). Sustainable Cities and Society, 2012(4): $35-40$.

[4] Hamdi Kessentini, Chiheb Bouden. Numerical and experimental study of an integrated solar collector with CPC Reflectors. Renewable Energy, 2013(57): 577-586.

[5] Li X, Dai Y J, Li Y, Wang R Z. Comparative study on two novel intermediate temperature $\mathrm{CPC}$ solar collectors with the U-shape evacuated tubular absorber. Solar Energy, 2013 (93): 220-234.

[6] Miriam Sánchez, Ivan G. Martínez, Eduardo A Rincón, María D. Duran. Design and Thermal-optic Analysis of an Ultra-solar Concentrator, Energy Procedia, 2014(57): 311-320.

[7] Wang P Y, Guan H Y, Liu Zh H, Wang G S, Zhao F, Xiao H SH. High temperature collecting performance of a new all-glass evacuated tubular solar air heater with U-shaped tube heat exchanger. Energy Conversion and Management, 2014(77): 315-323.

[8] Chang C, Li X, Zhang Q Q. Experimental and Numerical Study of the Heat Transfer Characteristics in Solar Thermal Absorber Tubes with Circumferentially Non-uniform Heat Flux. Energy Procedia, 2014 (49): 305-313.

[9] Wisut Chamsa-ard, Sukruedee Sukchai, Sorawit Sonsaree, Chatchai Sirisamphanwong. Thermal Performance Testing of Heat Pipe Evacuated Tube with Compound Parabolic Concentrating Solar Collector by ISO 9806 - 1. Energy Procedia, 2014 (56): 237-246.

[10] Wang J, Yin Zh Q, Qi J, Ma G B, Liu X J. Medium-temperature solar collectors with all-glass solar evacuated tubes. Energy Procedia Vol, 2015(70): 126-129.

[11] Deng Y C, Zhao Y H, Quan Zh H, Zhu T T. Experimental Study of the Thermal Performance for the Novel Flat Plate Solar Water Heater with Micro Heat Pipe Array Absorber. Energy Procedia, 2015 (70):41-48. 